\title{
International phase IV validation study of an EORTC quality of life questionnaire for testicular cancer patients: the EORTC QLQ- TC26
}

Monika Sztankay ${ }^{1,2^{*}}$ (D, Neil K. Aaronson ${ }^{3}$, Juan I. Arraras ${ }^{4}$, Umberto Basso ${ }^{5}$, Uros Bumbasirevic ${ }^{6}$, Fabio Efficace ${ }^{7}$, Johannes M. Giesinger ${ }^{1}$, Colin D. Johnson ${ }^{8}$, Marieke van Leeuwen ${ }^{3}$, Anne S. Oberguggenberger ${ }^{1}$,

Roman Sosnowski ${ }^{9}$, Teresa Young ${ }^{10}$, Bernhard Holzner ${ }^{1}$ and on behalf of the European Organisation for Research and Treatment of Cancer Quality of Life Group (EORTC QLG)

\begin{abstract}
Background: Given the high cure-rate for testicular cancer (TC) and the patients' young age, comprehensive evaluation of health-related quality of life (HRQOL) is an important consideration in this patient population. The EORTC QLQ-TC26 questionnaire module has been developed to supplement the EORTC QLQ-C30 in assessing TC-specific HRQOL in clinical trials and routine clinical practice. This international, multicentre phase IV validation study evaluated the psychometric properties of the new module.
\end{abstract}

Methods: This international, multicentre phase IV validation study enrolled testicular cancer patients from seven European countries. Patients completed the EORTC quality of life core questionnaire EORTC QLQ-C30 and the QLQ-TC26 at two consecutive time points and a debriefing questionnaire regarding the QLQ-TC26 after baseline assessment. Psychometric evaluation included examination of the hypothesized module scale structure, internal consistency and test-retest reliability, known-groups validity, responsiveness to change over time and cross-cultural acceptability.

Results: Data from 313 patients (mean age 38.6, SD 9.5) were analysed. All items exhibited a high completion rate with less than $2.4 \%$ missing values except for the sexuality items (up to $8.8 \%$ ). The confirmatory factor analysis supported the hypothesised scale structure of the QLQ-TC26. Test-retest reliability was good for 8 of 12 scales (intraclass correlation: R t1 |t2 ranged from 0.71-0.91) and four scales did not meet the acceptable criteria. Internal consistency was good for all twelve scales (Cronbach alpha $=0.79-0.90)$, except Communication (alpha $=0.67)$ and Sexual Functioning (alpha $=0.62)$. The module was able to distinguish clearly between patients with differing clinical status. Responsiveness to change over time was acceptable.

Conclusion: The EORTC QLQ-TC26 is a valid, reliable and well-accepted condition-specific questionnaire, supplementing the EORTC QLQ-C30, for the assessment of testicular cancer patients' HRQOL in clinical trials.

Keywords: Testicular cancer, Health-related quality of life, EORTC, Psychometric validation, Patient-reported outcome

* Correspondence: monika.sztankay@i-med.ac.at

${ }^{1}$ Medical University of Innsbruck, University Hospital Innsbruck, Psychiatry II,

Innsbruck, Austria

${ }^{2}$ Department of Psychiatry, Psychotherapy \& Psychosomatics, Medical

University of Innsbruck, Anichstrasse 35, Innsbruck, Austria

Full list of author information is available at the end of the article

(c) The Author(s). 2018 Open Access This article is distributed under the terms of the Creative Commons Attribution 4.0 International License (http://creativecommons.org/licenses/by/4.0/), which permits unrestricted use, distribution, and reproduction in any medium, provided you give appropriate credit to the original author(s) and the source, provide a link to the Creative Commons license, and indicate if changes were made. The Creative Commons Public Domain Dedication waiver (http://creativecommons.org/publicdomain/zero/1.0/) applies to the data made available in this article, unless otherwise stated. 


\section{Background}

Testicular cancer (TC) is characterised by a low prevalence (less than $1 \%$ of all male malignancies), a low mortality rate (less than $5 \%$ within five years), a young patient population (about two thirds $<40$ years) and increasing incidence rates $[1,2]$. Mortality rates have dropped significantly over the past three decades due to more effective treatment options, shifting the focus of interest on the oncological treatment's impact on patients' health-related quality of life (HRQOL). Approximately $75-80 \%$ of patients with seminoma present with stage I disease, with a cancer-specific survival rate of $97-100 \%$ and a low recurrence rate (below 6\%) under surveillance $[3,4]$. Likewise, $60 \%$ of the patients with non-seminoma germ cell TC are diagnosed at an early stage having a 14-48\% risk of recurrence within two years after surgery [5]. Treatment option encompass orchiectomy, retroperitoneal lymph node dissection with nerve sparing [6], chemotherapy with carboplatin (in early stage) [7] and Bleomycin, Etoposide and Cisplatin (for advanced disease) [8], as well as active surveillance [5].

Treatment strategies, although contributing to low mortality, are associated with various acute and long-term side effects [9]. These include gastrointestinal symptoms, peripheral neuropathy, Raynaud-like symptoms, hearing loss, tinnitus, heightened levels of fatigue, anxiety, cancer-related distress, sexual dysfunction, changes in body image and psychosocial problems [9-11]. Post-chemotherapy resection of residual masses can also result in chronic problems such as loss of antegrade ejaculation [12]. Survivors whose treatment included chemotherapy are at greater risk for long-term sequelae such as pulmonary toxicity, secondary malignant neoplasms, cardiovascular disease and decreased fertility [13]. Since the majority of TC survivors are at an age when fatherhood is a important consideration, fertility concerns and impaired sexual functioning may especially affect patients' HRQOL, as well as that of their partners $[14,15]$.

Given the high cure-rate and the patients' young age, evaluation of long-term HRQOL is an important consideration [16]. Previous studies comparing the HRQOL of men with $\mathrm{TC}$ with that of their general population peers have tended to use generic HRQOL questionnaires. These studies have typically reported similar levels of HRQOL for TC survivors and healthy men from the general population [17-20]. Generic HRQOL measures may, however, fail to assess symptoms and functional limitations specific to the TC patient population (e.g. infertility, body image and sexuality) and exhibit ceiling effects reducing the instruments' sensitivity and discriminant validity $[16,19]$. Standardising assessment of HRQOL with instruments developed according to rigorous questionnaire development guidelines guaranteeing a TC patient-centred approach, cross-cultural applicability and compatibility with existent cancer-specific core measures will enable comparability of results across studies and TC patient populations.

The pilot work of Fosså and colleagues [21] was a first important step towards the development of comprehensive HRQOL assessment of TC patients. However, their questionnaire has not been taken beyond the pilot stage of development and testing. Hoyt and colleagues have developed and tested a version of the Cancer Assessment for Young Adults (CAYA) questionnaire for young men with TC [22]. While the psychometric properties of this questionnaire appear to be good, it is questionable whether such a lengthy questionnaire can be widely adopted for use in clinical trials and daily clinical practice, where the economy of assessment burden is important. The developers of CAYA, therefore, propose the independent use of subscales which was supported by psychometric evaluation.

The European Organisation for Research and Treatment of Cancer (EORTC) Quality of Life Group has long used a standardized methodology to develop generic and condition-specific HRQOL questionnaires [23]. In the current paper, we report on the development and testing of the QLQ-TC26 for assessing the HRQOL of men with TC. This questionnaire has been developed according to the stepwise guidelines of the EORTC for questionnaire module development. This involves four phases: I) generation of relevant QOL issues, II) operationalization of the QOL issues into a set of items, III) pre-testing the questionnaire module; and IV) larger scale, international field testing of the psychometric properties of the module. Phases I to III of the development of the QLQ-TC26 were carried out between 2006 and 2011 and have been published previously [24]. This paper presents results of the final phase IV of developing this module.

\section{Methods \\ Sample}

Patients were recruited using the following inclusion and exclusion criteria: (1) diagnosis of testicular cancer, with or without relapse, (2) age 18 years or older, (3) sufficient reading ability to understand the questionnaire in their native language, (4) no obvious cognitive impairments, (5) provision of written informed consent, and (6) not participating in another HRQOL-related investigation that might interfere with the study.

To include patients during treatment as well as post-treatment, patients were recruited from two distinct groups. The on-treatment group (A) included patients undergoing surgery (with or without subsequent chemotherapy) who were assessed one to three days after surgery (T1on) and four weeks later (T2on). Although the protocol also allowed for recruitment of patients undergoing surgery then radiotherapy, no such patients presented 
during the enrolment period. The post-treatment group (B) was composed of patients who were at least one year post-treatment (T1post). They were assessed again after one week (T2post) in order to investigate test-retest reliability.

Patients were recruited from seven European countries (Austria, Italy, the Netherlands, Poland, Serbia, Spain, and the UK). Ethics committee approval was obtained at participating centres, following national requirements. Written informed consent was obtained from all participants, as required. The protocol was approved by the EORTC Quality of Life Group.

\section{Assessment instruments}

This study required completion of a case report form assessing clinical and sociodemographic data plus the following questionnaires and interview:

\section{EORTC QLQ-C30}

The EORTC QLQ-C30 [25] has been internationally validated and is one of the most widely used cancer-specific HRQOL-instruments. It is composed of 30 items organised into five functioning scales (physical, role, cognitive, emotional and social), a global QOL scale, three symptom scales (fatigue, nausea/vomiting and pain) and six single symptom items.

EORTC QLQ-TC26: Based on the results of Phase III of the development process [24], this testicular cancer-specific module includes 26 items organised into 7 multi-item scales and 6 single items addressing: treatment side effects (8 items), treatment satisfaction (2 items), future perspective (2 items), work/education problems (single item), physical limitations (single item), infertility (single item), family problems (single item), sexual activity (2 items), sexual enjoyment (2 items), sexual problems (2 items), communication (2 items), body image problems (single item) and testicular implant satisfaction (single item). Based on conceptual considerations the Job/ Education Problems scale hypothesised in phase III was split into two single-item scales (Job Problems and Physical Limitations) in phase IV.

The EORTC QLQ-TC26 is currently available in English, Dutch, German, Italian, Spanish, Serbian and Polish. Translations were performed according to the EORTC translation guidelines [26]. For both, the QLQ-C30 and the QLQ-TC26, high impairment is indicated by low scores for the functioning scales and high scores for the symptom scales.

\section{Debriefing questionnaire}

At T1, patients completed a debriefing questionnaire that assessed time required to complete the QLQ-TC26 and the QLQ-C30, whether any help was needed, and whether any of the items were upsetting, confusing or difficult to answer. Additional free text comments were invited.

\section{Data collection procedure}

Baseline assessment was done in the respective collaborating hospital upon receipt of informed consent, whereas follow-up assessment was performed either in the hospital or web-based at home Electronic data capture was available by means of the Computer-based Health Evaluation System (CHES [27]). CHES is a web-based software program that enables electronic data assessment in routine practice and clinical trials. It allows multicentre study monitoring providing electronic case report forms and web-based assessment of clinical and patient-reported data. CHES has already been implemented in other phase IV studies of the EORTC Quality of Life Group for the purpose of international field testing (https://ches.eortc.be/cms/module.html).

Those centres willing and able (depending on ethical approval and information technology infrastructure) to participate in electronic data capture were provided with access to the CHES data collection website. The website provided forms for entering clinical and sociodemographic data and allowed patients to complete the EORTC QLQ-C30 and the EORTC QLQ-TC26 via desktop computer or a tablet-PC. For the follow-up assessment, patients were provided with a username and password to complete the questionnaires online at home.

Prior to implementing web-based patient-reported data collection, a cognitive debriefing questionnaire and usability testing for CHES were conducted [28]. At institutions not participating in electronic assessment, data collection was performed using paper-and-pencil versions of the questionnaires.

\section{Statistical analysis}

Scale structure, internal consistency and test-retest reliability:

We conducted confirmatory factor analysis (CFA) to examine the hypothesised scale structure of the QLQ-T26.

We calculated standardised factor loadings for each item with regard to the corresponding scale and considered loadings above 0.40 to be sufficient [29]. Residual variance of single-item factors was set based on the test-retest reliability of the scales in the cancer group post-treatment (see below). Model-data-fit was assessed with the Comparative Fit Index and the Tucker-Lewis Index, with both indices considered to indicate good fit if they exceeded a value of 0.95 [30]. We also calculated the Root Mean Square Error of Approximation (RMSEA) as a further parameter for model-data-fit, with a value below 0.05 indicating a good fit [31]. 
We calculated Cronbach's alpha coefficients to assess the internal consistency reliability of each scale. Values above 0.70 were considered acceptable for purposes of group comparison [32].

Test-retest reliability was assessed in the post-treatment group only using the intraclass correlation coefficient (ICC), as well as calculating the percentage of absolute agreement for each scale. An ICC above 0.70 was regarded as adequate [32].

\section{Validity and responsiveness}

To assess convergent validity, we examined the correlation between single- and multi-item scales of the EORTC QLQ-TC26 and selected scales of the EORTC QLQ-C30. Correlations above 0.50 were considered to indicate convergent validity and correlations below 0.30 to indicate discriminant validity [33]. It was expected that those scales conceptually related would correlate substantially with one another. These scales were the QLQ-TC26 scales Treatment Side-Effects and Treatment Satisfaction vs. the QLQ-C30 functioning and symptom scales, Future Perspective (QLQ-TC26) vs Emotional Functioning and Social Functioning (QLQ-C30), Family Problems (QLQ-TC26) vs Social Functioning (QLQC30),

Physical Limitations (QLQ-TC26) vs Physical and Role Functioning (QLQ-C30), Job and Educational Problems (QLQ-TC26) vs Role Functioning and Financial Impact (both QLQ-C30) as well as the Communication and the Body Image scales (both QLQ-TC26) vs. Emotional Functioning (QLQ-C30). Additionally, we hypothesised that the QLQ-TC26 scales assessing sexuality (Sexual Activity, Functioning and Enjoyment) would show moderate correlations with the QLQ-C30 scales. Therefore, we assumed that correlations with those scales would qualify neither for convergent nor for discriminant validity.

Given the scoring as indicated above, for the Treatment Side Effect scale (QLQ-TC26), negative correlations were expected with the QLQ-C30 functioning and positive correlations with the QLQ-C30 symptom scales.

Known-group validity was tested with Student's t-test for independent samples, comparing patients on- and off-treatment and patients with metastatic versus non-metastatic disease. This was based on the assumption that patients off-treatment as well as without metastatic disease would perform better.

Responsiveness to change was analysed with linear mixed models comparing patients at the start of treatment and four weeks later.

The CFA was conducted with the software package $R$ [34] using the "Iavaan" package [35]. All other analyses were done with SPSS 21.0.

\section{Results}

\section{Sample characteristics}

From end of 2012 to 2015, a prospective sample of 313 TC patients was recruited in the UK $(N=130)$, Austria $(N=93)$, Poland $(N=25)$, Italy $(N=22)$, the Netherlands $(N=20)$, Serbia $(N=14)$ and Spain $(N=9) .113$ patients were still receiving (on-treatment group), 200 have already completed treatment (post-treatment group).

Mean age in the on-treatment group was 36.1 years (SD 9.9), in the post-treatment group 40.1 years (SD 9.0). Mean time since diagnosis was 6.7 months (SD 17.7) for patients on treatment, 5.4 years (SD 3.4) for patients post-treatment. About half of the patients were married or cohabitating and had at least 14 years of education (52.7\%). Most patients (76.4\%) were working full-time at the time of the assessment and had never been unemployed during the treatment phase (72.1\%). Forty-two percent did not have children, 20.3\% had one child, and $37.7 \%$ had two or more children. Most patients had non-metastatic disease (81.4\%), no recurrence $(85.8 \%)$ and a diagnosis of seminoma (62.5\%). At the time of the assessment, $63.9 \%$ of the patients were post-treatment (> 12 months) and $36.1 \%$ were receiving treatment (84.1\% surgery and $85.2 \%$ chemotherapy). Further details are given in Tables 1 and 2. Missing sociodemographic and clinical data were acquired from the respective clinical information systems.

\section{Compliance rates and debriefing results}

The dataset was screened for missing responses to the scoring items. Across all time points the largest percentage of missing responses was observed for items assessing sexuality (item 25: 8.8\% missing, item 24: 8.1\%, item 23: 6.3\%, item 22: $6.1 \%$, and item 21: $1.1 \%$ ). For items assessing treatment satisfaction percentage of missing responses was $2.4 \%$ (item 9) and $2.2 \%$ (item 10) respectively. All other items had less than 1\% missing responses.

Of the 313 patients, 173 completed the debriefing questionnaire at the baseline assessment. Questionnaire completion required, on average, $8.1 \mathrm{~min}$ (SD 4.2; range two to $30 \mathrm{~min}$ ). Only $6 \%$ of the patients required any help from family members or health care staff with completing the questionnaires. Twelve percent of the patients who completed the debriefing questionnaire indicated that at least one question was confusing or difficult to answer, and 3 patients found at least one upsetting. Comments applied primarily to questions related to sexual activity, which were perceived as sensitive but relevant.

\section{Usability testing of the CHES software for ePRO assessment}

Overall, $48 \%$ of all assessments were conducted electronically. Assuming similarity in reception and usage of ePRO in this comparably young patient group, a 
Table 1 Demographics of the patient sample $(n=313)$

\begin{tabular}{llll}
\hline & & Number & Perce \\
\hline Age: mean (SD) & $38.6(9.5)$ & & \\
Education & & 28 & 10.3 \\
& 10 years or less & 101 & 37.0 \\
& $11-13$ years & 144 & 52.7 \\
& 14 years or more & 40
\end{tabular}

Marital Status

$\begin{array}{ll}\text { Never married } & 113 \\ \text { Married or cohabiting } & 147 \\ \text { Separated/divorced } & 19 \\ \text { Other } & 18 \\ \text { Missing } & 16\end{array}$

Employment Status

Full-time
Part-time
Retired
In professional training
Sick leave
Unemployed
Other
Missing

Unemployment during treatment

$\begin{array}{lll}\text { Yes } & 78 & 27.9 \\ \text { No } & 202 & 72.1 \\ \text { Missing } & 33 & \end{array}$

Number of children

\begin{tabular}{lll}
0 & 116 & 42.0 \\
1 & 56 & 20.3 \\
2 & 74 & 26.8 \\
3 & 24 & 8.7 \\
4 & 6 & 2.2 \\
Missing & 37 & \\
\hline
\end{tabular}

Percentages are given for valid cases

consecutive subsample was questioned on the usability of electronic PRO assessment at the lead site in Austria $(n=15)$. Respondents (mean age 35.5 years, SD 7.5.; range 27-49) were highly educated $(n=12,80 \%$ with more than 11 years of education), mainly post-treatment $(\mathrm{n}=12,80 \%)$ and without metastases or recurrent disease. All respondents successfully navigated through the online questionnaire (e.g., skip questions, changing responses if so desired, proceeding to the next question, saving responses, etc). Three respondents reported minor issues concerning the visual display of the electronic questionnaire features (e.g., suggested larger font size and different icon colouring).
Table 2 Clinical patient characteristics

\begin{tabular}{|c|c|c|c|}
\hline & & Number & Percent \\
\hline \multirow[t]{2}{*}{ Treatment status } & On treatment & 113 & 36.1 \\
\hline & Post treatment & 200 & 63.9 \\
\hline \multirow[t]{2}{*}{ Time since diagnosis [in months] } & On treatment & $\begin{array}{l}\text { mean } \\
6.7\end{array}$ & SD 17.7 \\
\hline & Post treatment & $\begin{array}{l}\text { mean } \\
5.4\end{array}$ & SD 3.4 \\
\hline \multirow[t]{3}{*}{ Histological tumour type } & Seminoma & 162 & 62.5 \\
\hline & Non-Seminoma & 97 & 37.5 \\
\hline & Missing & 54 & \\
\hline \multirow[t]{3}{*}{ Metastases } & Metastases Yes & 50 & 18.6 \\
\hline & Metastases No & 219 & 81.4 \\
\hline & Missing & 44 & \\
\hline \multirow[t]{3}{*}{ Recurrence } & Recurrence Yes & 39 & 14.2 \\
\hline & Recurrence No & 235 & 85.8 \\
\hline & Missing & 39 & \\
\hline \multirow[t]{3}{*}{ Desire for a child } & No & 143 & 55.6 \\
\hline & Yes & 114 & 44.4 \\
\hline & Missing & 56 & \\
\hline \multirow[t]{3}{*}{ Testicular Implant } & No & 182 & 75.2 \\
\hline & Yes & 60 & 24.8 \\
\hline & Missing & 71 & \\
\hline \multirow[t]{3}{*}{ On-treatment Group: Surgery } & Surgery No & 14 & 15.9 \\
\hline & Surgery Yes & 74 & 84.1 \\
\hline & Missing & 25 & \\
\hline \multirow[t]{3}{*}{$\begin{array}{l}\text { On-treatment Group: } \\
\text { Chemotherapy }\end{array}$} & $\begin{array}{l}\text { Chemotherapy } \\
\text { No }\end{array}$ & 13 & 14.8 \\
\hline & $\begin{array}{l}\text { Chemotherapy } \\
\text { Yes }\end{array}$ & 75 & 85.2 \\
\hline & Missing & 25 & \\
\hline \multirow{3}{*}{$\begin{array}{l}\text { Post-treatment Group: } \\
\text { Previous Surgery }\end{array}$} & Surgery No & 9 & 5.5 \\
\hline & Surgery Yes & 154 & 94.5 \\
\hline & Missing & 37 & \\
\hline \multirow[t]{3}{*}{$\begin{array}{l}\text { Post-treatment Group: } \\
\text { Previous Chemotherapy }\end{array}$} & $\begin{array}{l}\text { Chemotherapy } \\
\text { No }\end{array}$ & 60 & 36.1 \\
\hline & $\begin{array}{l}\text { Chemotherapy } \\
\text { Yes }\end{array}$ & 106 & 63.9 \\
\hline & Missing & 34 & \\
\hline \multirow{3}{*}{$\begin{array}{l}\text { Post-treatment Group: } \\
\text { Previous Radiotherapy }\end{array}$} & Radiotherapy No & 157 & 94.0 \\
\hline & Radiotherapy Yes & 10 & 6.0 \\
\hline & Missing & 33 & \\
\hline
\end{tabular}

Percentages are given for valid cases

\section{Factor structure and reliability of the QLQ-TC26}

In the confirmatory factor analysis, all standardised factor loadings exceeded the threshold of 0.40 (0.6210.977), confirming the hypothesised scale structure of the QLQ-TC26. The comparative fit index $(\mathrm{CFI})=0.974$, the Tucker-Lewis fit index $(\mathrm{TLI})=0.963$, and the 
RMSEA $=0.046$ indicated good fit of the model and the data. Standardised factor loadings are provided in Table 3.

The threshold for test-retest reliability (0.70) was exceeded for all scales (0.71-0.91), except for Physical Limitations (0.67), Family Problems (0.65), and Treatment Satisfaction $(\mathrm{ICC}=0.48)$. The conditional scale Testicular Implant Satisfaction (0.69) could only be analysed in a subgroup of patients $(n=93)$.

For the multi-item scales, Cronbach's alpha coefficients ranged 0.62 for Sexual Functioning to 0.90 for Sexual Enjoyment. All but two scales (Communication and Sexual Functioning) exceeded the 0.70 criterion for group level use (see Table 3 for further details).

Each item showed the strongest correlation with the designated scale.

\section{Convergent and discriminant validity}

The Treatment Side-Effects scale showed strong correlations (all $p<0.001$ ) with the QLQ-C30 scales for Physical Functioning $(r=-0.55)$, Role Functioning $(r=0.50)$, Social Functioning $(r=-0.50)$, Emotional Functioning $(r=-0.51)$, Global QOL $(r=-0.55)$, Fatigue $(r=0.65)$ and Pain $(r=0.51)$, while the Treatment Satisfaction scale did not correlate significantly with any of the QLQ-C30 scales (all $r<0.07$ ).

For Future Perspective, the hypothesised correlation with Emotional Functioning failed to exceed the threshold for convergent validity of $0.50(r=0.49, p<0.001)$. In addition, the single item concerning Family Problems did not show the expected correlation with Social Functioning $(r=-0.47, p<0.001)$ and the Body Image scale failed to exceed the threshold for convergent validity with Emotional Functioning $(r=-0.44, p<0.001)$.

Table 3 Internal consistency, test-retest reliability and standardised factor loadings for the QLQ-TC26

\begin{tabular}{|c|c|c|c|c|}
\hline Scale & $\begin{array}{l}\text { Cronbach's } \\
\text { Alpha }\end{array}$ & $\begin{array}{l}\text { Test-retest } \\
\text { ICC }\end{array}$ & Item \# & $\begin{array}{l}\text { Standardised } \\
\text { Factor Loading }\end{array}$ \\
\hline \multirow[t]{8}{*}{ Treatment Side-effects } & 0.80 & 0.91 & Item 1 & 0.752 \\
\hline & & & Item 2 & 0.776 \\
\hline & & & Item 3 & 0.769 \\
\hline & & & Item 4 & 0.721 \\
\hline & & & Item 5 & 0.752 \\
\hline & & & Item 6 & 0.621 \\
\hline & & & Item 7 & 0.711 \\
\hline & & & Item 8 & 0.624 \\
\hline \multirow[t]{2}{*}{ Treatment Satisfaction } & 0.87 & 0.48 & Item 9 & 0.977 \\
\hline & & & Item 10 & 0.912 \\
\hline \multirow[t]{2}{*}{ Future Perspective } & 0.79 & 0.71 & Item 11 & 0.889 \\
\hline & & & Item 12 & 0.852 \\
\hline Job and Education Problems & & 0.81 & Item 13 & 0.810 \\
\hline Physical Limitation & & 0.67 & Item 14 & 0.670 \\
\hline Family Problems & & 0.65 & Item 15 & 0.650 \\
\hline Infertility & & 0.82 & Item 16 & 0.820 \\
\hline \multirow[t]{2}{*}{ Communication } & 0.67 & 0.80 & Item 17 & 0.708 \\
\hline & & & Item 21 & 0.944 \\
\hline Body Image Problems & & 0.75 & Item 18 & 0.750 \\
\hline \multirow[t]{2}{*}{ Sexual Activity } & 0.81 & 0.84 & Item 19 & 0.905 \\
\hline & & & Item 20 & 0.825 \\
\hline \multirow[t]{2}{*}{ Sexual Functioning } & 0.62 & 0.89 & Item 22 & 0.780 \\
\hline & & & Item 23 & 0.765 \\
\hline \multirow[t]{2}{*}{ Sexual Enjoyment } & 0.90 & 0.73 & Item 24 & 0.955 \\
\hline & & & Item 25 & 0.954 \\
\hline Testicular Implant Satisfaction ${ }^{a}$ & & 0.69 & Item 26 & \\
\hline
\end{tabular}

${ }^{\mathrm{a}}$ This conditional scale has been excluded from the confirmatory factor analysis $\mathrm{RMSEA}=0.046 ; \mathrm{CFI}=0.974 ; \mathrm{TLI}=0.963$ 
Job and Education Problems showed high correlations with Role Functioning $(r=-0.52)$ and Financial Impact ( $r=0.62, \mathrm{p}<0.001)$. Physical limitations showed convergent validity (all $\mathrm{p}<0.001$ ) with Physical Functioning $(\mathrm{r}$ $=-0.55)$, Role Functioning $(r=-0.67)$ and Global QOL $(r=-0.53)$.

Correlation between Communication and Emotional Functioning just exceeded the 0.30 cut-off for discriminant validity $(r=0.32, \mathrm{p}<0.001)$. All other correlations with the QLQ-C30 scales were low $(r<0.27)$. The single item on Infertility did not correlate significantly with any of the QLQ-C30 scales (all $r<0.23$ ).

\section{Known groups validity and responsiveness}

Known group comparisons were performed between patients on- and off-treatment and patients with metastatic versus non-metastatic disease. Comparing patients four weeks after start of treatment (T2on) with those in the post-treatment phase (T2post), we found the largest differences for Sexual Activity (40.5 vs 63.7, $\mathrm{p}<0.001$ ), Physical Limitations (36.1 vs 15.3, p <0.001), Family Problems (34.7 vs 22.8 points, $p=0.012$ ), Body Image Problems (23.6 vs 12.8 points, $p=0.039$ ) and Treatment Side-Effects (17.1 vs 9.3, $p=0.002)$. All differences were in favour of patients in the post-treatment phase.

The largest mean differences between patients post-treatment with and without previous metastatic disease were found for Sexual Enjoyment (59.3 vs 81.3 points, $p=0.001$ ), Sexual Activity (50.0 vs 67.9 points, $p=0.004)$ and Communication (71.4 vs 85.0 points, $p=$ 0.013). The difference in Treatment Satisfaction failed to reach statistical significance (78.7 vs 92.7 points, $p=$ 0.079). Further details are given in Table 4.
In the on-treatment group, the largest changes between the assessment at the start of treatment (T1on) and after four weeks (T2on) were found for Job and Education Problems (improvement from 32.4 to 16.1 points, $\mathrm{p}=0.001$ ), Sexual Activity (deterioration from 54.9 to 40.5 points, $\mathrm{p}=0.002$ ), Body Image (deterioration from 13.6 to 23.6 points, $p=0.016$ ), Sexual Enjoyment (deterioration from 78.6 to 70.6 points, $p=0.025$ ) and Treatment Side-Effects (deterioration from 12.3 to 17.1 points, $\mathrm{p}=0.002$ ). Please see Table 5 for further details.

\section{Discussion}

In this international phase IV field study, we evaluated the psychometric characteristics of the EORTC QLQ-TC26 module in a sample of 313 TC patients. In line with the EORTC Module Development Guidelines, these patients were from Southern, Western, Northern and Eastern Europe. No item was removed or changed from the phase III module. Based on conceptual considerations the Job/ Education Problems scale hypothesised in phase III was split into two single-item scales (Job Problems and Physical Limitations) in phase IV. The final QLQ-TC26 (see Additional file 1) comprises seven multi-item scales (treatment side effects, treatment satisfaction, future perspective, communication, sexual activity, functioning and enjoyment) and six single items (job and education problems, physical limitations, family problems, infertility, body image problems, testicular transplant satisfaction).

The hypothesised scale structure of the QLQ-TC26 was supported by confirmatory factor analysis and satisfactory internal consistency. All but two scales (Communication and Sexual Functioning) exceeded the 0.70

Table 4 QLQ-TC26 scores in patients with previous metastatic or non-metastatic disease post-treatment

\begin{tabular}{|c|c|c|c|c|c|c|}
\hline \multirow[b]{2}{*}{ EORTC QLQ-TC26 } & \multicolumn{2}{|c|}{$\begin{array}{l}\text { Previous metastatic disease } \\
N=21\end{array}$} & \multicolumn{2}{|c|}{$\begin{array}{l}\text { Previous non-metastatic disease } \\
N=157\end{array}$} & \multirow[b]{2}{*}{ t-statistic } & \multirow[b]{2}{*}{$p$-value } \\
\hline & Mean & SD & Mean & SD & & \\
\hline Treatment Side Effects & 15.3 & 21.8 & 8.2 & 12.3 & 1.461 & 0.158 \\
\hline Treatment Satisfaction & 78.7 & 31.2 & 92.7 & 19.7 & -1.860 & 0.079 \\
\hline Future Perspective & 65.9 & 26.1 & 67.3 & 26.6 & -0.233 & 0.816 \\
\hline Family Problems & 30.0 & 34.0 & 21.4 & 29.0 & 1.218 & 0.225 \\
\hline Infertility & 30.2 & 31.5 & 29.9 & 33.8 & 0.029 & 0.977 \\
\hline Communication & 71.4 & 26.9 & 85.0 & 22.8 & -2.510 & $0.013^{*}$ \\
\hline Body Image Problems & 22.2 & 32.2 & 11.3 & 20.5 & 1.520 & 0.143 \\
\hline Sexual Activity & 50.0 & 26.4 & 67.9 & 26.3 & -2.932 & $0.004^{* *}$ \\
\hline Sexual Functioning & 76.9 & 33.9 & 87.7 & 21.8 & -1.325 & 0.201 \\
\hline Job Education problems & 22.2 & 35.5 & 10.0 & 23.7 & 1.536 & 0.139 \\
\hline Physical limitations & 22.2 & 35.5 & 13.0 & 24.4 & 1.161 & 0.258 \\
\hline Sexual Enjoyment & 59.3 & 32.5 & 81.3 & 24.3 & -3.503 & $0.001^{* *}$ \\
\hline Testicular Implant Satisfaction & 66.7 & 38.5 & 66.7 & 32.9 & $<0.001$ & 1.000 \\
\hline
\end{tabular}

Note. ${ }^{*} p<.05,{ }^{* *} p<.01$ 


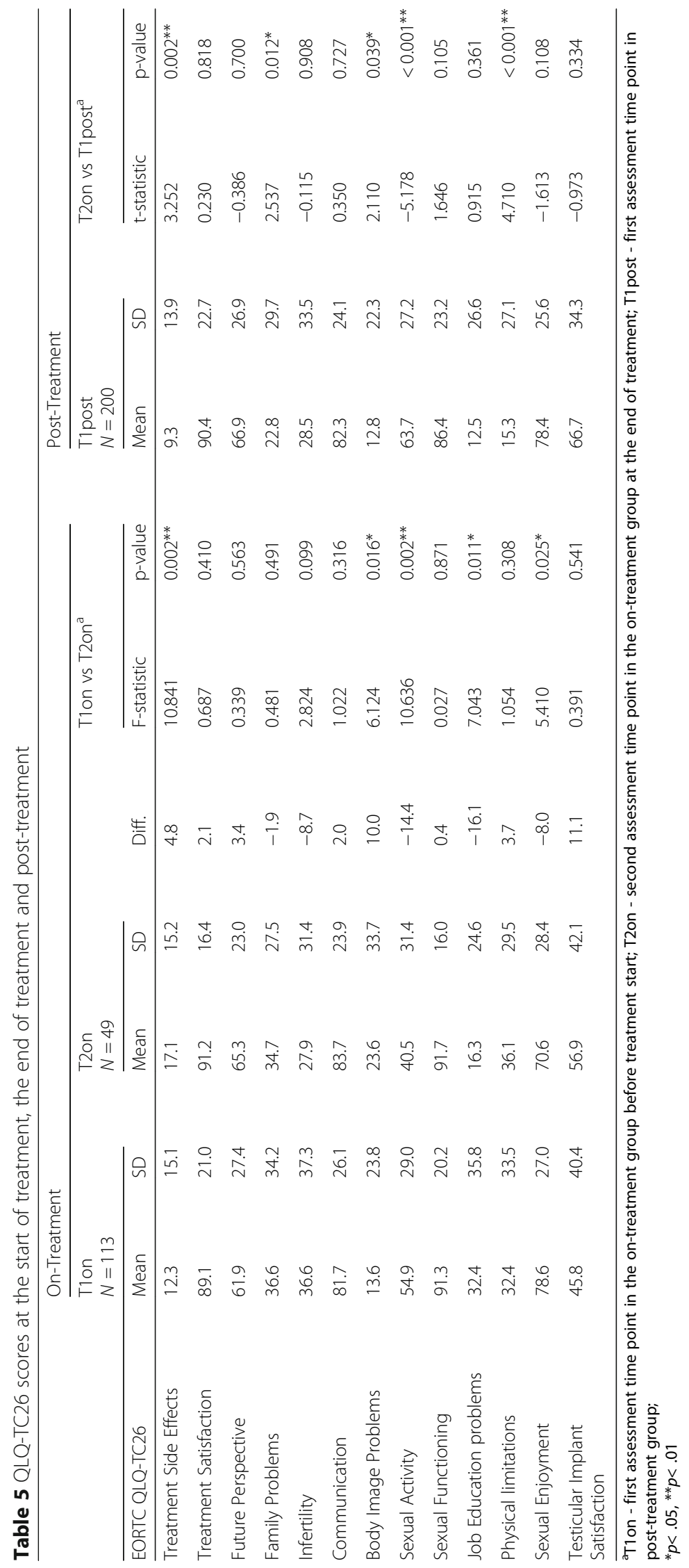


criterion for group level use concerning internal consistency. The two items of the Communication scale were found to be interdependent, indicating that patients able to talk about the disease were mostly able to talk about sexuality, but not necessarily the other way round. For Sexual Functioning a substantial proportion of patients reported no impairments at all, while those reporting issues frequently had either problems with ejaculation or with erection, but not always both. Patients did comment on the sensitive nature of items about sexuality, but agreed that these items were relevant. Percentage of missing items on sexuality is comparable or even lower than in other EORTC QOL modules [36].

The test-retest reliability analysis of the questionnaire met the ICC threshold for excellent reliability (0.90) for the Treatment Side-Effects scale. The threshold for good reliability of 0.70 was almost met or exceeded for the remaining multi-item scales, except the Treatment Satisfaction scale which exhibited the lowest test-retest reliability. This might be related to the issue of discontinuation of clinical care and a change to self-managed follow-up.

While internal consistency measured by Cronbach Alpha coefficients was not good for all scales, the structural equation model showed good factor loadings of the individual items on the respective scales supporting the overall scale structure of the module.

Most of the hypotheses on correlations between the QLQ-TC26 and the QLQ-C30 scales could be confirmed which indicates good convergent and discriminant validity for the QLQ-TC26 scales. Correlations for the Family Problems (vs. Social Functioning) and Body Image scale (vs. Emotional Functioning) closely missed the predefined thresholds for convergent validity. For Family Problems, this may relate to the fact that the QLQ-C30 scale measures actual impairment of social relations, whereas the QLQ-TC26 assesses patients' concerns about possible problems in this area. For the Communication scale correlations with the QLQ-C30 scales indicated discriminant validity as expected, with the exception only of the correlation with Emotional Functioning that slightly exceeded the threshold. Furthermore, the QLQ-C30 does not cover issues concerning sexuality which are, however, relevant for TC patients.

Known-group analyses confirmed the ability of the QLQ-TC26 to discriminate between subgroups of patients who differed clinically with regard to treatment status and extent of disease. As expected, patients in long-term follow up had better scores in the scales Treatment Side-Effects, Family Problems, Body Image Problems, Sexual Activity and Physical Limitations when compared to patients at the end of treatment. This is in accordance with studies showing that HRQOL of TC survivors improves after treatment [19]. In our study, metastatic disease, however, results in higher impairment in Sexual Enjoyment, Sexual Activity as well as Communication in patients with metastatic disease post-treatment.

Changes of scores were hypothesised in the course of the treatment trajectory and were broadly congruent with clinical expectations. When comparing patients' HRQOL before start of treatment and four weeks later, results indicated deterioration in Body Image, Sexual Activity, Sexual Enjoyment and Treatment Side Effects, while Job and Educational Problems improved following diagnosis. It might be hypothesised that the latter may be the result of increased adaptation to the situation, after having dealt with administrative aspects such as sick leave and the engagement of supportive services.

Based on the results of this phase IV study, assessment with the QLQ-TC26 is recommended when investigating changes in disease-specific HRQOL across the treatment trajectory in clinical trials or clinical routine. It is also appropriate for assessing the HRQOL of patients in the early post-treatment survivorship period (defined herein as up to 1 year following completion of treatment). Where the focus of a study is on the HRQOL of longer term TC survivors, another type of survivorship questionnaire may be needed. The EORTC Quality of Life Group is currently developing a questionnaire for assessing the QOL of cancer survivors including those suffering from TC. In the previous phases of the questionnaire development, it was decided not to define treatment phase-specific scales as this would have complicated and limited the consistency of longitudinal QOL assessment from diagnosis to follow-up [24]. Assessments of the HRQOL in young adults might benefit from combinations with available questionnaires such as the CAYA [22].

A limitation of this study was that patients treated with radiotherapy were only included in the off-treatment group, which might be attributable to the current clinical recommendations, proposed by international guidelines [7]. Published data on long-term toxicity and the increased risk for second non-germ cell malignancies indicate that adjuvant radiotherapy should no longer be recommended as first-line adjuvant treatment for patients with stage I seminoma [37] and younger patients [7]. It is, however, still considered as a treatment option in patients with TC stage IB, IIA and IIB, though, diagnosis at the latter stage is less common. Such is metastatic disease in TC patients, resulting in a limited subsample.

Missing data might be explained by the fact that extraction of missings from the clinical information systems was of varying success across participating centres. Another issue was the set-up of the clinical report form. Several variables had to be derived from the patients themselves (e.g. marital status) and could not be acquired from the medical charts. To reduce the odds for 
missings, these parts of the clinical report form (meant to be completed by the study assistant approaching the patient) should have been administered as part of the patient questionnaire.

Despite the above mentioned limitations, with regard to the scale structure, the current structure is well-defined from a conceptual point and it was supported empirically by the structural equation model. While the EORTC QLQ-TC26 has begun to see use in clinical trials [EudraCT2014-003930-17] [NCT02304575], future studies should aim for further application of the EORTC QLQ-TC26 to assess utility of the measure in more versatile cultural settings (e.g. in non-European regions and in ethnic minorities) and to evaluate its applicability in a more dynamic assessment approach supplemented with relevant validated subscales.

The strengths of this study are the systematic development and validation across various linguistic and cultural contexts, reflecting the rigorous EORTC module development guidelines, The QLQ-TC26 assesses not only somatic, but also psychological and psychosocial issues in order to provide a comprehensive overview of TC patients' disease- and treatment-related HRQOL. Patient feedback from the debriefing questionnaire indicated that the large majority of patients did not have any difficulties with and were not confused by the items, nor did they find the questionnaire items upsetting. Finally, the availability of an electronic version of the questionnaire using the CHES software can reduce the resources required for data collection and entry, and minimise data entry errors. Usability testing in a subsample of participating patients indicated that patients have few if any problems in completing the questionnaire digitally.

\section{Conclusion}

The results of this international phase IV study provide evidence for the reliability and the validity of the EORTC QLQ-TC26. We recommend it to be used in conjunction with the QLQ-C30 in clinical trials as well as in daily clinical routine for the assessment of HRQOL across the treatment trajectory.

\section{Additional file}

Additional file 1: Specimen EORTC QLQ-TC26 (PDF 28 kb)

\section{Abbreviations}

CFA: Confirmatory factor analysis; CFI: Comparative fit index;

CHES: Computer-based Health Evaluation System; EORTC QLQ-C30: European Organisation of Research and Treatment of Cancer Quality of Life

Questionnaire Core 30; EORTC QLQ-TC26: European Organisation of Research and Treatment of Cancer Quality of Life Questionnaire Testicular Cancer 26; ePRO: Electronic patient-reported outcome; HRQOL: Health-related quality of life; ICC: Intraclass correlation coefficient; RMSEA: Root Mean Square Error of Approximation

\section{Acknowledgements}

We would like to thank Marek Czeladzki, Melanie Winterbotham and the Italian Germ-Cell Cancer Group (U. De Giorgi, Meldola; A.L. Gentile, Teramo; D. Dongiovanni, Asti; G. Palmieri, Napoli) for help with data collection.

\section{Ethics approval and consent participate}

Ethics committee approval was required and obtained from the Medical University of Innsbruck Ethics Committee (Austria), the Medisch-Ethische Toetsingscommissie van Stichting Nederlands Kankerinstituut-Het Antoni van Leeuwenhoek Ziekenhuis (The Netherlands), the National Research Ethics Services Committee South Central - Portsmouth (UK), the Comitato Etico - Istituto Oncologico Veneto (I.R.C.C.S; Italy), the Ethics Committee of the Faculty of Medicine University of Belgrade (Serbia) and the Ethics Committee of Clinical Research in Navarre (Spain), following national requirements. Informed written consent was obtained from all participants, as required. The protocol was approved by the EORTC Quality of Life Group. All procedures followed were in accordance with the ethical standards of the responsible committee on human experimentation (institutional and national) and with the Helsinki Declaration of 1964 and later versions.

\section{Funding}

The study was financially supported by Grant No. 001/2011 from the EORTC Quality of Life Group. The work of Johannes M. Giesinger was funded by a grant from the Austrian Science Fund (FWF \#P 26930).

\section{Availability of data and materials}

The datasets used and analysed during the current study are available from the corresponding author on reasonable request and with permission of the co-authors.

\section{Authors' contributions}

The current study was designed by NKA, JMG, ASO and BH. Patient data was collected and assembled by NKA, JMG, JIA, UB, UrB, FE, CDJ, MvL, RS, TY and $\mathrm{BH}$ who also coordinated data assessment. JMG performed the statistical analysis. MS, JMG and BH interpreted the data. MS and JMG were major contributors in writing the manuscript. All authors read, revised and approved the final manuscript.

Consent for publication

Not applicable.

\section{Competing interests}

Bernhard Holzner is an owner of the intellectual property rights of the software CHES. None of the other authors has a conflict of interest to declare.

\section{Publisher's Note}

Springer Nature remains neutral with regard to jurisdictional claims in published maps and institutional affiliations.

\section{Author details}

${ }^{1}$ Medical University of Innsbruck, University Hospital Innsbruck, Psychiatry II, Innsbruck, Austria. ${ }^{2}$ Department of Psychiatry, Psychotherapy \&

Psychosomatics, Medical University of Innsbruck, Anichstrasse 35, Innsbruck, Austria. ${ }^{3}$ Division of Psychosocial Research \& Epidemiology, The Netherlands Cancer Institute, Amsterdam, The Netherlands. ${ }^{4}$ Medical Oncology Department, Hospital of Navarre, Navarre, Spain. ${ }^{5}$ Medical Oncology 1, Istituto Oncologico Veneto (IOV) IRCCS, Padova, Italy. ${ }^{6}$ Clinic of Urology, Clinical Center of Serbia, University of Belgrade, Belgrade, Serbia. ${ }^{7}$ Health Outcomes Research Unit, Italian Group for Adult Hematologic Diseases (GIMEMA), Rome, Italy. ${ }^{8}$ University Surgical Unit, University of Southampton, Southampton University Hospitals, Southampton, UK. ${ }^{9}$ Urooncology Department, Maria Sklodowska Curie Memorial Cancer Hospital, Warsaw, Poland. ${ }^{10}$ Jackson Macmillan Centre, East \& North Hertfordshire NHS Trust including Mount Vernon Cancer Center, Northwood Middlesex, UK. 
Received: 21 March 2018 Accepted: 4 September 2018

Published online: 12 November 2018

\section{References}

1. Shanmugalingam T, Soultati A, Chowdhury S, Rudman S, Van Hemelrijck M. Global incidence and outcome of testicular cancer. Clin Epidemiol. 2013;5: 417-27.

2. Trabert B, Chen J, Devesa SS, Bray F, McGlynn KA. International patterns and trends in testicular cancer incidence, overall and by histologic subtype, 1973-2007. Andrology. 2015;3(1):4-12.

3. Aparicio J, Maroto P, Garcia del Muro X, Sanchez-Munoz A, Guma J, Margeli M, Saenz A, Sagastibelza N, Castellano D, Arranz JA, et al. Prognostic factors for relapse in stage I seminoma: a new nomogram derived from three consecutive, risk-adapted studies from the Spanish Germ Cell Cancer Group (SGCCG). Ann Oncol. 2014;25(11):2173-8.

4. Tandstad T, Smaaland R, Solberg A, Bremnes RM, Langberg CW, Laurell A, Stierner UK, Stahl O, Cavallin-Stahl EK, Klepp OH, et al. Management of seminomatous testicular cancer: a binational prospective population-based study from the Swedish norwegian testicular cancer study group. J Clin Oncol. 2011:29(6):719-25.

5. Rajpert-De Meyts E, McGlynn KA, Okamoto K, Jewett MA, Bokemeyer C. Testicular germ cell tumours. Lancet. 2016;387(10029):1762-74.

6. Wells H, Hayes MC, O'Brien T, Fowler S. Contemporary retroperitoneal lymph node dissection (RPLND) for testis cancer in the UK - a national study. BJU Int. 2017;119(1):91-9.

7. Albers P, Albrecht W, Algaba F, Bokemeyer C, Cohn-Cedermark G, Fizazi K, Horwich A, Laguna MP, Nicolai N, Oldenburg J. Guidelines on testicular Cancer: 2015 update. Eur Urol. 2015;68(6):1054-68.

8. Calabro F, Albers P, Bokemeyer C, Martin C, Einhorn LH, Horwich A, Krege S, Schmoll HJ, Sternberg CN, Daugaard G. The contemporary role of chemotherapy for advanced testis cancer: a systematic review of the literature. Eur Urol. 2012;61(6):1212-21.

9. Abouassaly R, Fossa SD, Giwercman A, Kollmannsberger C, Motzer RJ, Schmoll HJ, Sternberg CN. Sequelae of treatment in long-term survivors of testis cancer. Eur Urol. 2011;60(3):516-26.

10. Joly F, Heron JF, Kalusinski L, Bottet P, Brune D, Allouache N, Mace-Lesec'h J, Couette JE, Peny J, Henry-Amar M. Quality of life in long-term survivors of testicular cancer: a population-based case-control study. J Clin Oncol. 2002; 20(1):73-80.

11. Haugnes HS, Bosl GJ, Boer H, Gietema JA, Brydoy M, Oldenburg J, Dahl AA Bremnes RM, Fossa SD. Long-term and late effects of germ cell testicular cancer treatment and implications for follow-up. J Clin Oncol. 2012;30(30): 3752-63.

12. Wortel RC, Ghidey Alemayehu W, Incrocci L. Orchiectomy and radiotherapy for stage I-II testicular seminoma: a prospective evaluation of short-term effects on body image and sexual function. J Sex Med. 2015;12(1):210-8.

13. Gilligan T. Health and quality of life among survivors of testis cancer. Urol Oncol. 2015:33(9):390-1.

14. Rossen P, Pedersen AF, Zachariae R, von der Maase $H$. Sexuality and body image in long-term survivors of testicular cancer. Eur J Cancer. 2012:48(4):571-8

15. Jankowska M. Sexual functioning of testicular cancer survivors and their partners - a review of literature. Rep Pract Oncol Radiother. 2011;17(1):54-62.

16. Smith AB, Butow $P$, Olver I, Luckett $T$, Grimison P, Toner GC, Stockler MR, Hovey E, Stubbs J, Turner S, et al. The prevalence, severity, and correlates of psychological distress and impaired health-related quality of life following treatment for testicular cancer: a survivorship study. J Cancer Surviv. 2016; 10(2):223-33.

17. Fleer J, Hoekstra HJ, Sleijfer DT, Tuinman MA, Klip EC, Hoekstra-Weebers JE. Quality of life of testicular cancer survivors and the relationship with sociodemographics, cancer-related variables, and life events. Support Care Cancer. 2006:14(3):251-9.

18. Mykletun A, Dahl AA, Haaland CF, Bremnes R, Dahl O, Klepp O, Wist E, Fossa SD. Side effects and cancer-related stress determine quality of life in longterm survivors of testicular cancer. J Clin Oncol. 2005;23(13):3061-8.

19. Rossen PB, Pedersen AF, Zachariae R, von der Maase H. Health-related quality of life in long-term survivors of testicular cancer. J Clin Oncol. 2009; 27(35):5993-9.

20. Kim C, McGlynn KA, McCorkle R, Erickson RL, Niebuhr DW, Ma S, Graubard B, Aschebrook-Kilfoy B, Barry KH, Zhang Y. Quality of life among testicular cancer survivors: a case-control study in the United States. Qual Life Res. 2011:20(10):1629-37.

21. Fossa SD, Moynihan C, Serbouti S. Patients' and doctors' perception of longterm morbidity in patients with testicular cancer clinical stage I. A descriptive pilot study. Support Care Cancer. 1996;4(2):118-28.

22. Hoyt MA, Cano SJ, Saigal CS, Stanton AL. Health-related quality of life in young men with testicular cancer: validation of the Cancer assessment for young adults (CAYA). J Cancer surviv. 2013;7(4):630-40.

23. Fayers P, Bottomley A. Quality of life research within the EORTC-the EORTC QLQ-C30. European Organisation for Research and Treatment of Cancer. Eur J Cancer. 2002;38(Suppl 4):S125-33.

24. Holzner B, Efficace F, Basso U, Johnson CD, Aaronson NK, Arraras JI, Smith $A B$, Chow E, Oberguggenberger AS, Bottomley A, et al. Cross-cultural development of an EORTC questionnaire to assess health-related quality of life in patients with testicular cancer: the EORTC QLQ-TC26. Qual Life Res. 2013;22(2):369-78.

25. Aaronson NK, Ahmedzai S, Bergman B, Bullinger M, Cull A, Duez NJ, Filiberti A, Flechtner H, Fleishman SB, de Haes JC, et al. The European Organization for Research and Treatment of Cancer QLQ-C30: a quality-of-life instrument for use in international clinical trials in oncology. J Natl Cancer Inst. 1993; 85(5):365-76.

26. Koller M, Aaronson NK, Blazeby J, Bottomley A, Dewolf L, Fayers $\mathrm{P}$, Johnson C, Ramage J, Scott N, West K. Translation procedures for standardised quality of life questionnaires: the European Organisation for Research and Treatment of Cancer (EORTC) approach. Eur J Cancer. 2007;43(12):1810-20.

27. Holzner B, Giesinger JM, Pinggera J, Zugal S, Schopf F, Oberguggenberger AS, Gamper EM, Zabernigg A, Weber B, Rumpold G. The computer-based health evaluation software (CHES): a software for electronic patient-reported outcome monitoring. BMC Med Inform Decis Mak. 2012;12:126.

28. Coons SJ, Gwaltney CJ, Hays RD, Lundy JJ, Sloan JA, Revicki DA, Lenderking WR, Cella D, Basch E. Recommendations on evidence needed to support measurement equivalence between electronic and paper-based patientreported outcome (PRO) measures: ISPOR ePRO good research practices task force report. Value Health. 2009;12(4):419-29.

29. Ferguson E, Cox T. Exploratory factor analysis: a Users' guide. Int J Select Assess. 1999;6:1-55.

30. Hu LT, Bentler PM. Cutoff criteria for fit indexes in covariance structure analysis: conventional criteria versus new alternatives. Struct Equ Modeling. 1999;6:1-55.

31. Schermelleh-Engel $\mathrm{KMH}$, Müller $\mathrm{H}$. Evaluating the fit of structural equation models: tests of significance and descriptive goodness-of-fit measures. Meth Psychol Res. 2003;8(2):23-74

32. Fayers PMMD. Quality of life. Assessment, analysis and interpretation. Chichester: Wiley; 2013.

33. Nunnally JCBI, editor. Psychometric theory. 3rd ed. New York: McGraw-Hill; 1994.

34. A language and environment for statistical computing. Available from: http://www.R-project.org/. Accessed 6 Nov 2018.

35. Rosseel $Y$. lavaan: an $R$ package for structural equation modeling. J Stat Softw. 2012;48(2):1-36.

36. Greimel $E$, Nordin A, Lanceley A, Creutzberg CL, van de Poll-Franse LV, Radisic VB, Galalae R, Schmalz C, Barlow E, Jensen PT, et al. Psychometric validation of the European Organisation for Research and Treatment of Cancer quality of life questionnaire-endometrial Cancer module (EORTC QLQ-EN24). Eur J Cancer. 2011;47(2):183-90.

37. Albers P, Albrecht W, Algaba F, Bokemeyer C, Cohn-Cedermark G, Fizazi K, Horwich A, Laguna MP. EAU guidelines on testicular cancer: 2011 update. Eur Urol. 2011;60(2):304-19.

Ready to submit your research? Choose BMC and benefit from:

- fast, convenient online submission

- thorough peer review by experienced researchers in your field

- rapid publication on acceptance

- support for research data, including large and complex data types

- gold Open Access which fosters wider collaboration and increased citations

- maximum visibility for your research: over $100 \mathrm{M}$ website views per year

At $\mathrm{BMC}$, research is always in progress.

Learn more biomedcentral.com/submissions 